\title{
IMPROVED IMAGING OF COVERED KARST WITH THE MULTI-ELECTRODE RESISTIVITY IMPLANT TECHNIQUE
}

\author{
David Harro \\ Geo3Group, 2410 Success Drive, Suite 7, Odessa, FL 33556, david.harro@geo3group.com
}

\section{Sarah Kruse}

Dept. of Geology, University of South Florida, 4202 E. Fowler Ave., SCA-528, Tampa, FL 33620, skruse@usf.edu

\begin{abstract}
Electrical resistivity tomography (ERT, also called ERI) is commonly used to identify geologic features associated with sinkhole formation. In covered karst terrain, however, it can be difficult to resolve the depth to top of limestone with this method. This is due to the fact that the sediments mantling the limestone are often clayrich and highly conductive. The resistivity method has limited sensitivity to resistive zones beneath conductive zones. This sensitivity can be improved significantly with electrodes implanted at depths near the top of limestone, in addition to readings at the surface. Deep electrodes are installed with direct push technology, placing an ERT array in the clay-rich karst cover near the top limestone surface contact. This method, which we are calling Multi-Electrode Resistivity Implant Technique (MERIT), offers the promise of significantly improved resolution of epikarst and cover collapse development zones at the limestone surface sediment interface in heterogeneous karst environments. The technique could also help reduce the effects of cultural features typically encountered by surface electrical resistivity surveys in urban environment.
\end{abstract}

The results of a case study sinkhole investigation in west-central Florida show the applicability of MERIT. At this site the resistivity array length is restricted to 60 meters. The depth to the top of the limestone lies at $\sim 15$ meters. Electrodes were implanted both at the surface and at 10 meters depth every 3.3 meters along a profile 50 meters long. The combination of both surface and deep measurements improves the resolution of the sediment-limestone interface over that from surface measurements alone.

\section{Introduction}

Geophysical methods for imaging structures in covered karst often have had limited success because the depth to the sediment -rock interface was greater than the depth of resolution of the survey. This is especially true in urban areas where restrictions in the surface array length limit the depth of penetration. In urban areas cultural features can also have a considerable impact on the geophysical results and complicate interpretation of geophysical results. However the need for full understanding of the sediment/carbonate rock interface in highly heterogeneous karst settings is often a critical problem and geophysical methods remain the most efficient alternative for high resolution imaging between borings.

The resolution depth of electrical resistivity imaging (ERI) surveys is limited by the distance between the furthest electrodes involved in any single reading (e.g. Milsom, 2003). A simple cost effective technique to address this depth restriction is to place electrodes at depth (e.g. Pidlisecky et al., 2006). To fully exploit the available array length, we install electrodes at uniform intervals at depth across the array. With this MultiElectrode Resistivity Implant Technique (MERIT), deeper features can be imaged. In covered karst, we can then target the sediment /carbonate rock surface interface to image epikarst or possible cover collapse development. By combining measurements with surface and deep electrodes we can also improve imaging of the sediment column above the karst development. In cases where sinkholes are stabilized by grouting, this method could be used to help verify sediment stabilization.

\section{MERIT}

With MERIT, the depth of penetration of a resistivity survey can approximately be extended by lowering the electrodes closer to the depth of target horizons (Figure 1). For example, a 33 meter ERI surface array can be expected to resolve features to approximately 7 meters in depth, with greater depths at the center of the array and shallower depths near the ends of the array. If, for example, the bedrock surface is 10 meters below land surface (bls) then the surface geophysical survey will 


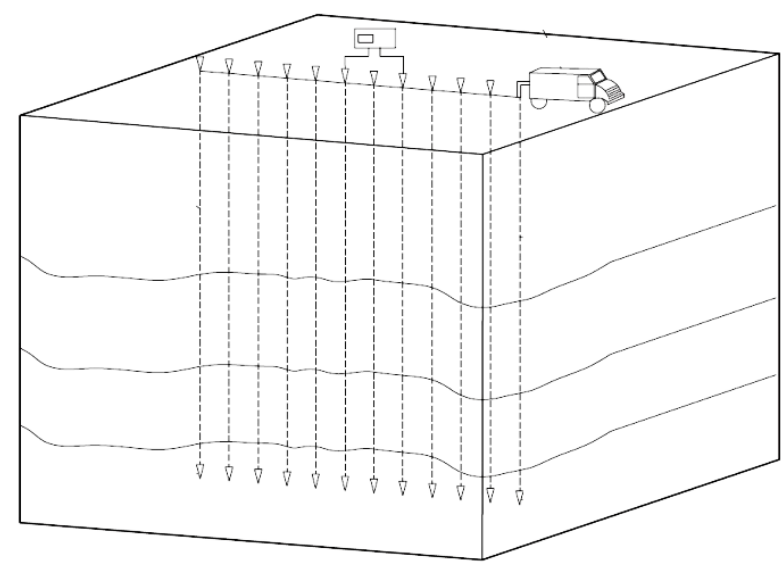

Figure 1. MERIT method schematic. Electrodes are emplaced at the surface and at depth with direct push technology.

not image the sediment /carbonate rock interface except perhaps at the center of the array. This geophysical survey has missed its target depth by 3 to 7 meters along much of the array. By lowering the ERI array through the unconsolidated sediment, MERIT can get closer to the intended target. Because current can now flow above the electrode array as well as below it, measurements are now responsive to overlying sediments as well as the underlying sediment/carbonate rock contact. To image the underlying contact and voids in the limestone requires that the resistivity of the overlying sediments is simultaneously resolved. This is done by also taking measurements with electrodes implanted at the surface, as in a conventional array.

With the MERIT method, electrodes are installed with direct push technology. Upwards of 150 linear meters of implant installation can be performed in a single day. Referring again to our example for the top of limestone surface at 10 meters bls a 28 electrode implant would require 277 linear meters of direct push drilling at a cost of approximately 1.5 days of direct push installation. The additional cost of installation is offset by the enhanced understanding of specific areas of karst development. In this example, without the implanted electrodes the limestone contact could at best only be identified in the center of the array. Lateral variability and features associated with the development of cover collapse sinkholes could not be imaged.

With time-lapse resistivity profiling (repeated profiles in the same location), the MERIT method could be used for imaging sinkhole development and the effects of ground stabilization efforts. Successive images could be acquired during the sinkhole formation process, and pre and post compaction grouting.

\section{Case Study - Bordeaux Apartments Tampa, Florida}

The Bordeaux apartments in Tampa, Florida received national news coverage in July of 2010 after a car in the parking lot was swallowed by a 7 meter diameter cover collapse sinkhole (Figure 2). The sinkhole was adjacent to a 20-unit apartment building and affected part of the structure. Over several weeks the sinkhole continued to enlarge, further threatening the existing structure.

\section{Florida geology and sinkholes}

Sinkhole occurrences such as this one are numerous in Florida, and have resulted in substantial number of insurance claims for damages to structures (Schmidt 2005). The development of karst on the Florida carbonate platform has been related to sea level changes of up to 92 to 109 meters below current sea level (Tihansky 1999). These sea level changes have resulted in carbonate rocks being exposed to karst processes (Beck 1986, 1991). In

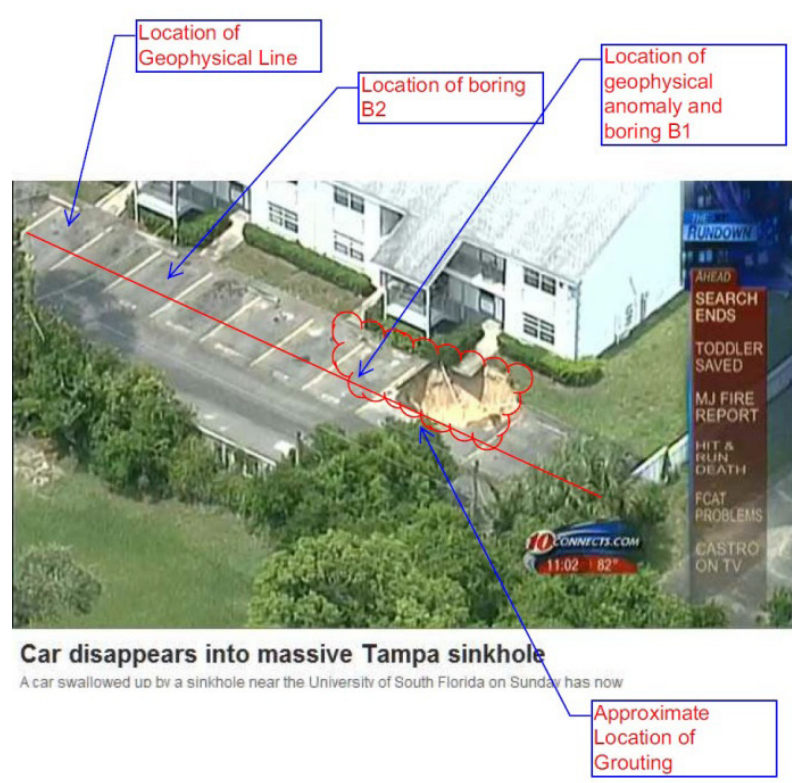

Figure 2. Bordeaux Apartments sinkhole, Tampa, FL. Resistivity profile location shown with red line. Boring results are shown in Figure 3. Geophysical surveying was limited to the apartment complex grounds; the spatial constraints on survey dimensions are clear from the photo. North is to the lower right of the photo. The sinkhole was filled with sand at the time of the survey. 
Hillsborough County, Florida the karst processes have created sinkholes that have affected many structures, irrigation and drinking water wells and farm lands. The cover-collapse sinkhole distribution (FCIT 2008) and development in Hillsborough County is primarily in geologic areas of the county where the cover is 10 to 65 meters thick (Sinclair et al. 1985). The cover is characteristically comprised of undifferentiated Quaternary sediments that overlie Tertiary clay deposits identified as the Undifferentiated Hawthorn Group; these in turn overlie the carbonate limestone of the Tampa Member (Hawthorn Group) that consists predominantly of limestone with subordinate dolostone, sand and clay (Scott et al. 2001). The area of the test case is known locally for a high development of sinkhole occurrences.

\section{Standard Penetration Test borings}

Over 23 standard penetration test (SPT) borings were performed on the entire property of the Bordeaux Apartments. Results of borings B1 and B2 near the resistivity line are shown in Figure 3.

In general the site-specific geology was comprised of three basic stratums. From the surface, Stratum 1 consists of 7 meters or less of undifferentiated quaternary sediments of mainly sands. Stratum 2 is comprised of clays and sandy clays of thickness ranging from 6 to 10 meters thick. These sediments vary in clay content and contain limestone fragments near the intersection with the sediment/rock interface. Stratum 3 is comprised of limestone. Depth to limestone in the borings varies from 10 to 19 meters bls. Analysis of the post-remedial underpinning program for 108 underpins indicated the Stratum 3 depths around the perimeter of the structure averaged from 12 to 15 meters bls, however at one location ,top of limestone bedrock was encountered at 75 meters bls.

Additional analysis came from the grouting program (e.g. Sowers, 1996). A total of 62 compaction grouting points were also installed around the perimeter of the structure and ranged from an average of 12 to 15 meters bls with a single location reaching 44 meters bls. Loss of circulation was recorded at all grout point locations at the point of contact with Stratum 3, except the grout point that extended to 44 meters in which a loss of circulation was recorded starting at 3.3
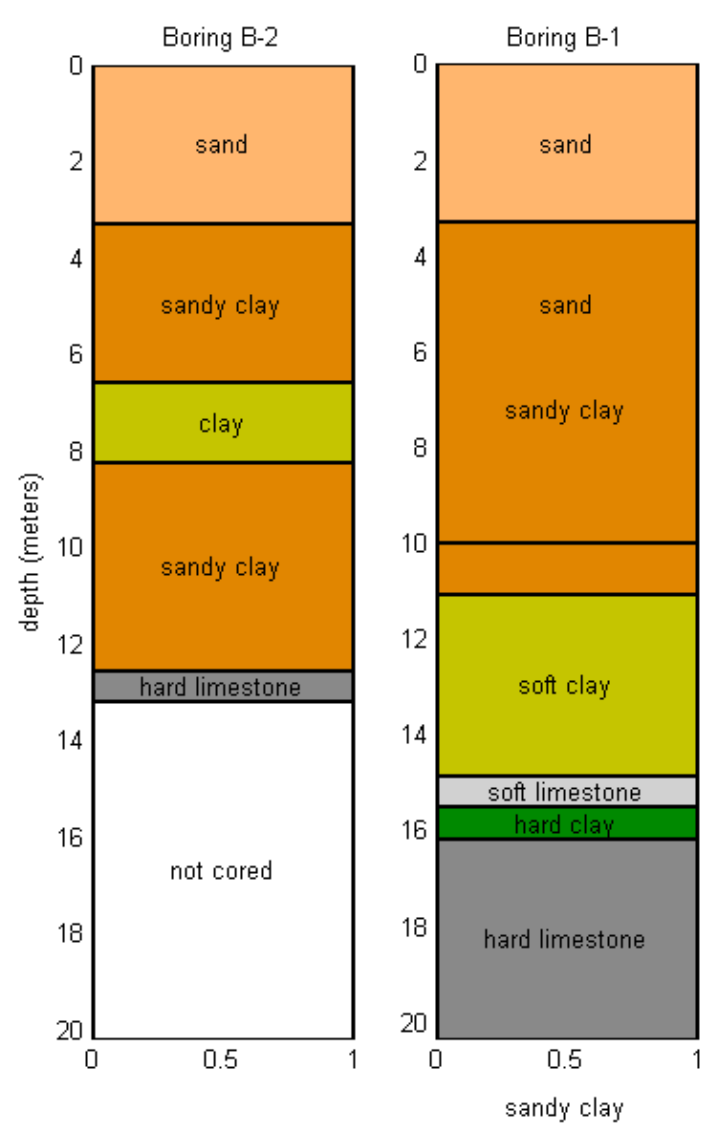

Figure 3. Borings $B 2$ and $B 1$ (location shown in Figure 1). The uppermost sand constitutes Stratum 1, the intermediate layers constitute Stratum 2, and the underlying limestone constitutes Stratum 3 as discussed in the text.

meters bls and continuing through the entire casing installation. The two deeper locations were located on the east and west sides respectively of the structure affected by the sinkhole activity.

\section{Conceptual Model}

The Bordeaux Apartments test site lies in an area identified as having numerous sinkhole incidences. A conceptual model of the sinkhole formation (Beck 1988) was developed prior to the geophysical testing. Two possible cover collapse geometries were considered:

- The sinkhole forms part of a collapse conduit system, which would facilitate flow through the drainage basin to the Hillsborough River to the east of the subject property. The conduit system could possibly extend under the affected building.

- The sinkhole development is isolated to a specific vertical and radial extent. 


\section{MERIT Profile}

At the time of approval for the use of MERIT, remedial efforts of underpinning and compaction grouting were in progress, and the sinkhole had been filled in with clean sands. It was determined the metal underpinning would have an adverse effect on the MERIT if the profile was positioned too close to the structure. Additional restrictions on profile location included underground power lines and property boundaries. Thus it was determined to place the MERIT profile along the eastern edge of the sinkhole (Figure 2).

The MERIT array was comprised of 18 surface ERI locations and 18 implant locations at 3.3 meters spacing. The MERIT implants were set at 10 meters depth and were in contact with Hawthorn Formation clays and clayey sands of Stratum 2 and within 3.3 meters of the average depth to the top of limestone formation of Stratum3. Two sets of surveys were conducted, one set pre-grouting, and one set post-grouting. In each set of surveys, conventional dipole-dipole and inverse-schlumberger geometries were recorded for both surface and buried arrays, and an additional set of readings were taken in which surface electrodes were used as current dipoles and potential measurements were recorded with buried dipoles.
Data were inverted using Res2Dinvx64 version 4.0 software from Geotomo, Inc. The presence of deep electrodes required the use of the borehole geometry algorithms within the Res2Dinv package (Geotomo, Inc. 2011).

Figure 4 shows the results of the resistivity profile inversion using only the surface electrodes. With surface electrodes, there is no indication of the more resistive limestone below the clays. Figure 5 illustrates the reason for this, namely that the surface survey has very low sensitivity to the 10-13 meter depth of the limestone contact.

Figures 6 and 7 show that when data from the deep electrodes are added, higher resistivities associated with the limestone are imaged (reds and yellows at depth). The sensitivity of the inversion at the 10-13 meter depths of interest is increased dramatically.

Post-grouting surveys looked very similar to pregrouting surveys. The volume of grout used ( $\sim 30$ cubic yards) did not significantly change resistivity images.

\section{Discussion and Conclusions}

There are significant misfits between depths of sandto-clay and clay-to-limestone contacts observed in

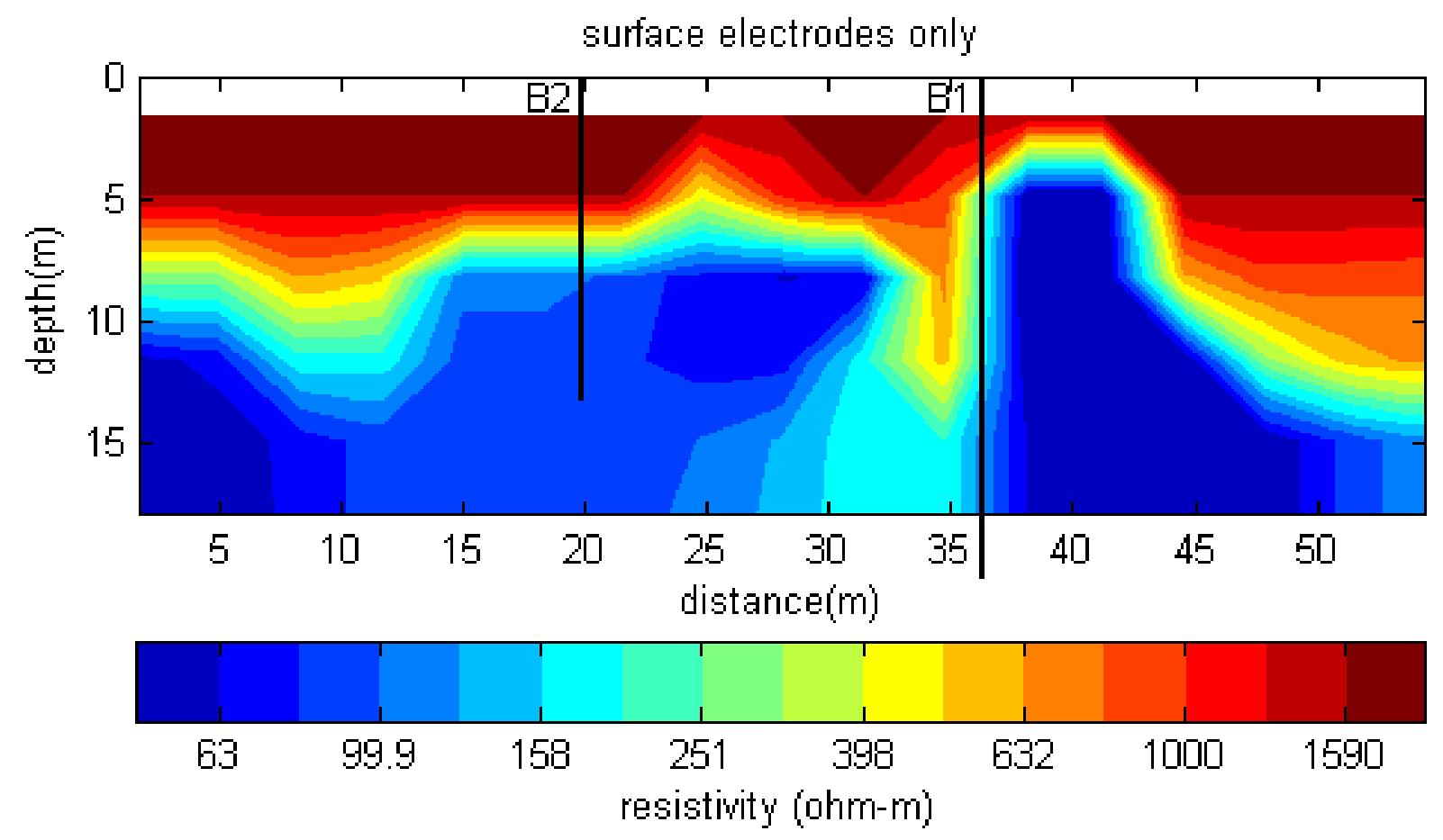

Figure 4. Resistivity profile inversion using data from surface electrodes only. (See Figure 2 for location of profile and borings B 1 and B2.) The rms error on this inversion is $11.7 \%$. Only the central 53 meters of the 59 $\mathrm{m}$-long profile are shown. There is no indication of higher resistivities at depth associated with the limestone. 

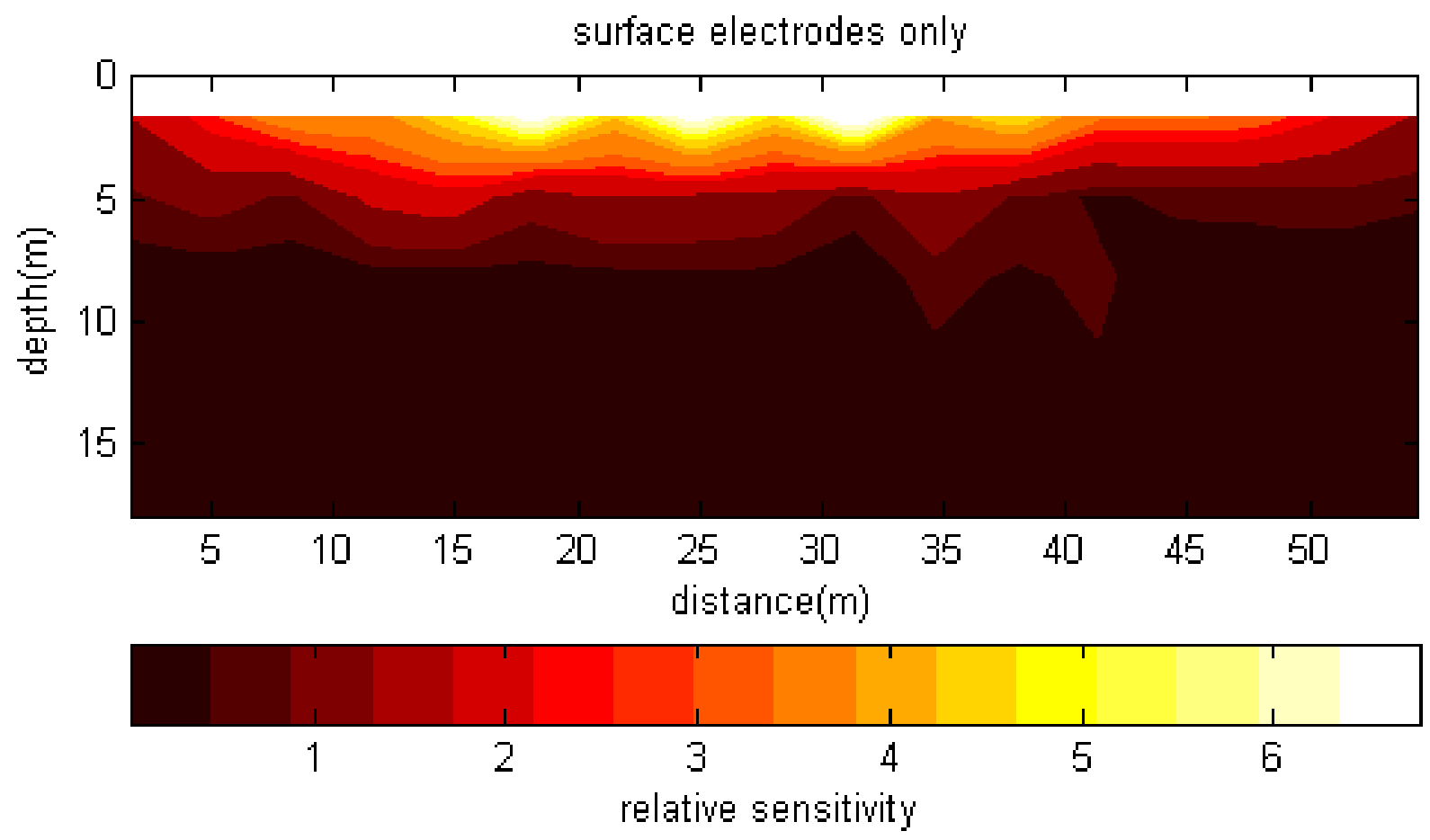

Figure 5. Relative sensitivity of the resistivity survey using data from surface electrodes only. The sensitivity is a measure of how well the resistivity in a given part of the model can be resolved by the data collected. Sensitivity values are normalized by dividing by the mean, and are unitless (Geotomo, Inc. 2011). Resistivities in yellow areas are well-resolved, resistivities in dark red areas are poorly resolved. The surface survey has limited sensitivity below 8 meters depth.

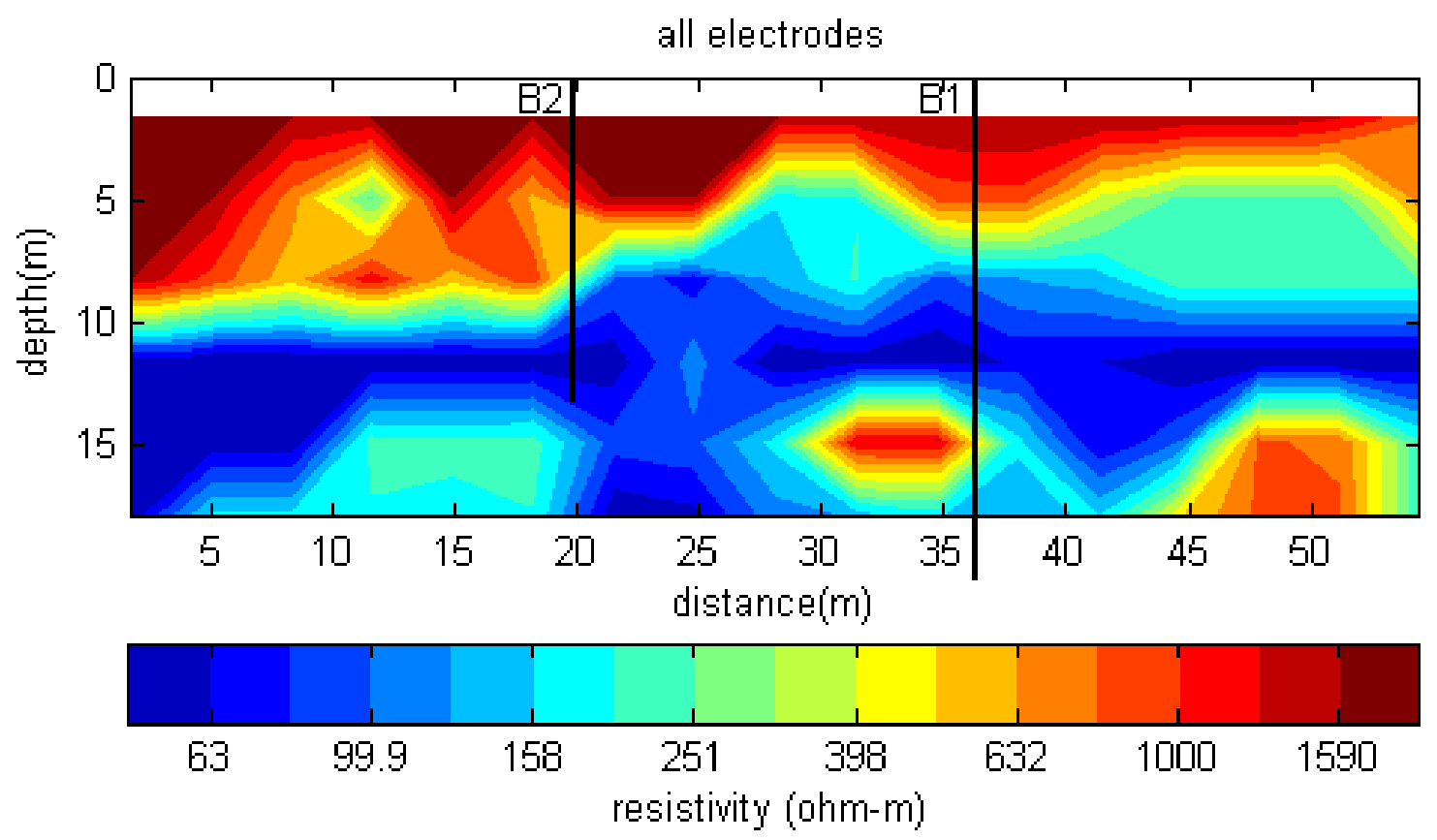

Figure 6. As for Figure 4, but incorporating readings from electrodes at depth. This inversion includes the traditional surface dipole-dipole array, the equivalent dipole-dipole array at 10 meters depth, and readings with current electrodes at surface and potential electrodes at depth. In this inversion, zones of higher resistivity are observed at depths where the limestone was reached in SPT borings. 


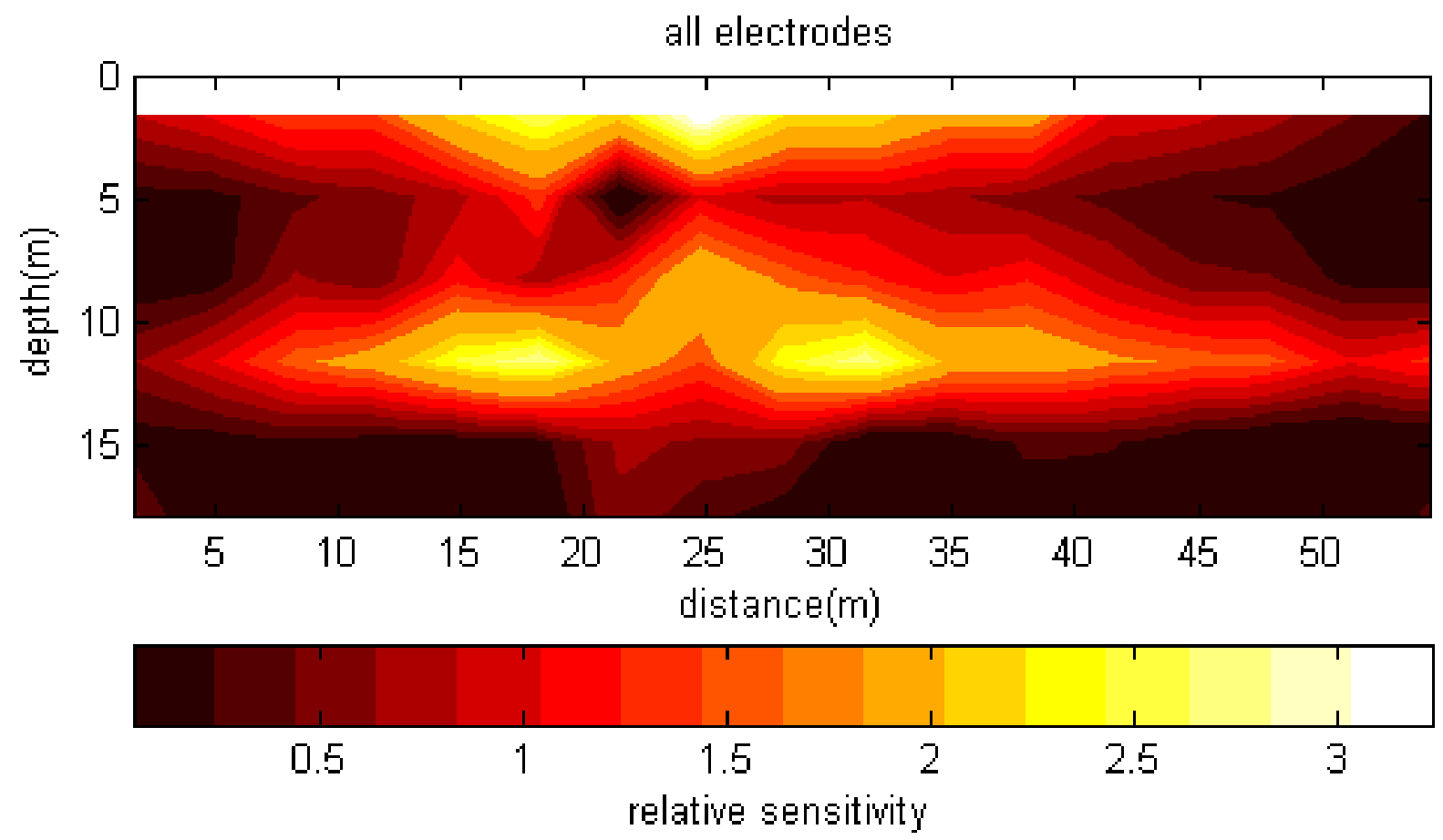

Figure 7. Relative sensitivity of the resistivity survey data when incorporating readings from electrodes at 10 meters depth. Compare to Figure 5; note the increased sensitivity at depths of 10-13 meters.

the borings (Figure 3) and in transitions in resistivity (Figures 4 and 6). These misfits may be due to significant local 3D heterogeneity that cannot be modeled in the $2 \mathrm{D}$ inversion process, or to gradational changes in resistivity across zones of changes in lithology that are more gradual than noted in the boring logs, or to problems in the inversion of relatively noisy data. We note the "cross data", in which current was injected at one level and potential readings were made at another level, were particularly noisy. Optimal acquisition and inversion procedures are a topic of ongoing investigation. With additional case studies and synthetic modeling in progress, we anticipate better understanding of the sources of noise and uncertainty in the resistivity images.

Despite the current limitations, it is clear that at the Bordeaux Apartments the top of the limestone could not be imaged with surface electrodes alone, but could be seen with the addition of the MERIT deep electrodes. The MERIT approach has increased the depth of resolution, and permitted imaging of the target horizon despite the spatial limitation of the site.

\section{Acknowledgements}

We are grateful to Henok Kiflu and Geoview, Inc. for help in field data acquisition. Comments from Lewis Land and an anonymous reviewer improved this manuscript.

\section{References}

Beck BF. 1988. Environmental and Engineering Effects of Sinkholes - The Processes Behind the Problems. Environmental Geology and Water Sciences 12 (2): 71-78.

Beck BF, Sinclair WC. 1986. Sinkholes in Florida: An Introduction. Florida Sinkhole Research Institute at the University of Central Florida College of Engineering Report 85-86-4.

Beck BF, Sayed S. 1991. The Sinkhole Hazard in Pinellas County: A Geologic Summary for Planning Purposes. Florida Sinkhole Research Institute at the University of Central Florida College of Engineering Report 90-91-1.

Florida Center for Instructional Technology. 2008. Sinkhole Maps of Florida Counties.

Geotomo, Inc. 2011. RES2DINVx64 ver. 4.00 with 64bit support Rapid 2-D Resistivity and IP inversion using the least-squares method. Malaysia. Geotomo Software.

Milsom J. 2003. Field Geophysics. United Kingdom: John Wiley \& Sons Ltd.

Pidlisecky A, Knight R, Haber E. 2006. Cone-based electrical resistivity tomography. Geophysics 71 (4). 
Schmidt W. 2005. Geological and Geotechnical Investigation Procedures for Evaluation of the Causes of Subsidence Damage in Florida. Florida Geological Survey Special Publication 57.

Scott TM et al. 2001. Geologic Map of the State of Florida. Florida Geologic Survey: Map Series 146.

Sinclair W. C. et al. 1985. Types, Features, and Occurrence of Sinkholes in the Karst of WestCentral Florida. US Geological Survey Water Resources Investigations Report 85-4126.

Sowers GF. 1996. Building on Sinkholes: design and construction of Foundations in Karst terrain. New York (NY): ASCE Press.

Tihansky AA. 1999. Sinkholes, West-Central Florida. U.S. Geological Survey Karst Interest Group Proceedings, St. Petersburg, Florida, February 1316, 2001: US Geological Survey Water-Resources Investigations Report 01-4011. 
